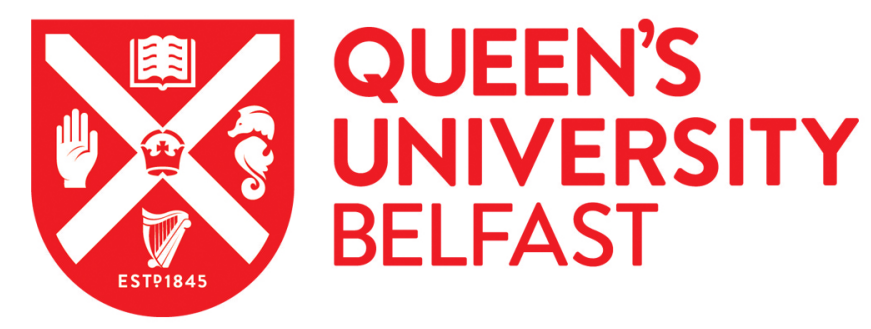

\title{
Changes in immediate early gene expression in the rat brain after unilateral lesions of the hippocampus
}

Jenkins, T., Amin, E., Brown, M. W., \& Aggleton, J. P. (2006). Changes in immediate early gene expression in the rat brain after unilateral lesions of the hippocampus. Neuroscience, 137(3), 747-759.

\section{Published in:}

Neuroscience

Queen's University Belfast - Research Portal:

Link to publication record in Queen's University Belfast Research Portal

\section{General rights}

Copyright for the publications made accessible via the Queen's University Belfast Research Portal is retained by the author(s) and / or other copyright owners and it is a condition of accessing these publications that users recognise and abide by the legal requirements associated with these rights.

Take down policy

The Research Portal is Queen's institutional repository that provides access to Queen's research output. Every effort has been made to ensure that content in the Research Portal does not infringe any person's rights, or applicable UK laws. If you discover content in the Research Portal that you believe breaches copyright or violates any law, please contact openaccess@qub.ac.uk. 


\section{CHANGES IN IMMEDIATE EARLY GENE EXPRESSION IN THE RAT BRAIN AFTER UNILATERAL LESIONS OF THE HIPPOCAMPUS}

\author{
T. A. JENKINS, ${ }^{a 1}$ E. AMIN, ${ }^{a} M$. W. BROWN ${ }^{b}$ \\ AND J. P. AGGLETON ${ }^{a *}$ \\ a School of Psychology, Cardiff University, Cardiff, Wales, CF10 3YG, UK \\ ${ }^{b}$ Department of Anatomy, University of Bristol, Medical School, Bristol, \\ BS8 1TD, UK
}

\begin{abstract}
Activity of the immediate early genes c-fos and zif268 was compared across hemispheres in rats with unilateral, excitotoxic lesions of the hippocampus (dentate gyrus and CA fields 1-4). Counts of the protein products of these genes were made shortly after rats performed a test of spatial working memory in the radial-arm maze, a task that is sensitive to bilateral lesions of the hippocampus. Unilateral hippocampal lesions produced evidence of widespread hypoactivity. Significant reductions in immediate early gene counts were observed within all three anterior thalamic nuclei, as well as the entorhinal, perirhinal, and postrhinal cortices, and much of the subicular complex. In contrast, no observable changes were detected in the anterior cingulate, infralimbic or prelimbic cortices, as well as several amygdala nuclei, even though many of these regions receive projections from the subiculum. Instead, the immediate early gene changes were closely linked to sites that are thought to be required for successful task performance, with both immediate early genes giving similar patterns of results. The findings support the notion that the anterior thalamic nuclei, hippocampus, and parahippocampal cortices form the key components of an interdependent neuronal network involved in spatial mnemonic processing. () 2005 Published by Elsevier Ltd on behalf of IBRO.
\end{abstract}

Key words: hippocampus, Fos, zif268, spatial memory, parahippocampal region, anterior thalamus.

Both anatomical and neuropsychological findings point to the functional importance of the hippocampal connections with the medial diencephalon (Delay and Brion, 1969; Gaffan, 1992a; Aggleton and Brown, 1999). Efferents from the subiculum convey hippocampal information to the medial diencephalon, principally via the fornix (Meibach and Siegel, 1977; Aggleton et al., 1986; Amaral and Witter, 1995). These efferents terminate in the mammillary bodies, anterior thalamic nuclei and rostral midline thalamic

1 Present address: Howard Florey Institute of Experimental Physiology and Medicine, University of Melbourne, Victoria, 3010, Australia.

${ }^{*}$ Corresponding author. Tel: +44-0-29-2087-4563; fax: +44-0-292087-4858.

E-mail address: Aggleton@cardiff.ac.uk (J. P. Aggleton).

Abbreviations: $A D$, anterodorsal nucleus; Alp, insular cortex; $A M$, anteromedial nucleus; AUDp, primary auditory area; AV, anteroventral nucleus; BL, basolateral nucleus; IEG, immediate early gene; La, lateral nucleus; MD, mediodorsal thalamic nucleus; PBS, phosphatebuffered saline; PBST, $0.1 \mathrm{M}$ phosphate-buffered saline containing $0.2 \%$ Triton $\mathrm{X}-100$; VISp, primary visual area.

0306-4522/06 $\$ 30.00+0.00$ ๑ 2005 Published by Elsevier Ltd on behalf of IBRO doi:10.1016/j.neuroscience.2005.09.034 nuclei, and these same thalamic nuclei may reciprocally influence the hippocampal formation. There is growing evidence that hippocampal-diencephalic interactions are critical for episodic memory in humans and spatial memory in animals (Barbizet, 1963; Gaffan, 1992b; Aggleton and Saunders, 1997; Parker and Gaffan, 1997; Warburton et al., 2000, 2001). Much of this evidence has come from measuring the cognitive and behavioral consequences of damage to particular components of this circuit. The present study forms part of a series of experiments that has mapped the more global consequences of disruption to this circuit by measuring immediate early gene (IEG) expression in rats. Previous studies have reported the effects of lesions in the fornix (Vann et al., 2000c) and anterior thalamic nuclei (Jenkins et al., 2002a,b, 2004), while the current study describes the consequences of hippocampal lesions on IEG expression in other brain areas. By this means it is possible to appreciate the wider impact of these lesions, not only on other parts of the hippocampal-diencephalic circuit but also in other regions implicated in learning and memory.

Immunohistochemical methods were used to measure the activity of two IEGs, c-fos and zif268. The IEG, c-fos, is widely spread throughout the brain and has been used as a marker of neuronal activation (Dragunow and Faull, 1989). There is, in addition, evidence that the c-fos gene may have a more specific contribution to learning processes (Herdegen and Leah, 1998; Tischmeyer and Grimm, 1999). Performing the radial-arm maze task leads to increased Fos, the protein product of c-fos, in a network of interlinked sites including the anterior thalamic nuclei, hippocampus, subicular complex and retrosplenial cortices (Vann et al., 2000a,b; He et al., 2002). It has also been found that blocking c-fos expression in the dorsal hippocampus impairs spatial memory formation in the radial-arm maze $(\mathrm{He}$ et al., 2002), so providing more direct evidence for the importance of this IEG. zif268 complements c-fos in that it is also widely expressed in the brain and, like c-fos, has repeatedly been linked to learning and memory (Okuno and Miyashita, 1996; Guzowski et al., 2001; Hall et al., 2001; Jones et al., 2001; Bozon et al., 2002; Davis et al., 2003). While the time course of zif268 expression overlaps with c-fos (Zangenehpour and Chaudhuri, 2002), these two IEGs are differentially expressed and so do not provide redundant information (Wisden et al., 1990).

In the present study, rats with unilateral hippocampal lesions were trained on a spatial working memory task in the radial-arm maze and Fos levels compared across hemispheres. The advantage of studying unilateral hippocampal lesions is that the rats can still perform the task 
to high levels of accuracy (Warburton et al., 2001) and within-subject comparisons provide the closest behavioral control. These considerations are relevant as rats with bilateral hippocampal lesions are severely impaired on the radial-arm maze task (Jarrard, 1978; Olton et al., 1978), and so it would not be possible to match their abnormal arm choices with those of a control group also performing the radial arm maze task. It is, however, the case that the intact hemisphere cannot be regarded as normal as it will have lost commissural inputs from the contralateral hippocampus. An additional, smaller group of rats received the same surgical procedure but IEG levels were measured in rats taken straight from the home-cage. Comparisons between the home-cage and radial-arm maze groups made it possible to determine whether the experimental condition had raised IEG levels, as expected (Vann et al., 2000a,b). A raise in IEG levels would help to rule out floor effects as a possible cause of any apparent failures of the hippocampal lesions to alter IEG levels.

\section{EXPERIMENTAL PROCEDURES}

\section{Subjects}

The main experiment involved 11 male hooded Lister rats (Harlan, Oxon, UK) weighing from $281 \mathrm{~g}$ to $342 \mathrm{~g}$. A further four hooded Lister rats $(281-334 \mathrm{~g})$ were used to examine baseline levels of Fos and zif268 ('home-cage controls'). Approximately 14 days after surgery animals were food deprived to $85 \%$ of their freefeeding body weight and maintained at this level throughout the experiment. Water was available ad libitum. Animals were housed under diurnal conditions (14-h light/10-h dark) and all testing occurred at a regular time during the light period. Animals were thoroughly habituated to handling before the study began. All experiments were carried out in accordance with the UK Animals (Scientific Procedures) Act, 1986 and associated guidelines. All efforts were made to minimize the number of animals used and their suffering.

\section{Apparatus}

Testing was carried out in an eight-arm radial maze, which consisted of an octagonal central platform $(34 \mathrm{~cm}$ diameter) and eight equally spaced radial arms ( $87 \mathrm{~cm}$ long, $10 \mathrm{~cm}$ wide). The base of the central platform and the arms were made of wood, while panels of clear Perspex ( $24 \mathrm{~cm}$ high) formed the walls of the arms. At the end of each arm was a food well $(2 \mathrm{~cm}$ in diameter and $0.5 \mathrm{~cm}$ deep). At the start of each arm was a clear Perspex guillotine door (12 cm high) that controlled access in and out of the center area. Each door was attached to a pulley system enabling the experimenter to control access to the arms. All animals were tested in the same rectangular room $(295 \mathrm{~cm} \times 295 \mathrm{~cm} \times 260 \mathrm{~cm})$ that contained salient visual cues, such as high contrast stimuli and geometric shapes on the walls.

\section{Surgery}

Rats were anesthetized by i.p. injection of pentobarbitone sodium (Sagatal) at a dose of $60 \mathrm{mg} / \mathrm{kg}$. Animals were then placed in a stereotaxic frame (David Kopf Instruments, Tujunga, USA) and the scalp cut and retracted to expose the skull. A craniotomy was made above the saggital sinus and the dura cut to expose the cortex above the target region.

Unilateral hippocampal lesions were produced by injections of $0.63 \mathrm{M}$ ibotenic acid (Biosearch Technologies, Tujunga, USA), dissolved in phosphate buffered saline ( $\mathrm{pH} 7.4)$, made via a $1 \mathrm{ml}$ syringe (Hamilton, Bonaduz, Switzerland) and placed into 14 sites within the same hemisphere as described previously (Coutureau et al., 1999; Ward-Robinson et al., 2001). The left and right hemispheres were used as surgical targets in different animals. The stereotaxic coordinates relative to bregma with the incisor bar set at flat skull to the horizontal plane were [AP, LAT, HT (from top of cortex), volume $(\mathrm{ml})]$ : $-5.4, \pm 5.0,-6.1,0.08 ;-5.4, \pm 5.0$, $-5.3,0.08 ;-5.4, \pm 5.0,-4.5,0.09 ;-5.4, \pm 4.2,-3.9,0.1 ;-4.7$, $\pm 4.5,-6.5,0.05 ;-4.7, \pm 4.0,-7.2,0.1 ;-4.7, \pm 4.0,-3.5,0.05$; $-3.9, \pm 3.5,-2.7,0.1 ;-3.9, \pm 2.2,-3.0,0.1 ;-3.9, \pm 2.2,-1.8$, $0.1 ;-3.1, \pm 3.0,-2.7,0.1 ;-3.1, \pm 1.4,-3.0,0.1 ;-3.1, \pm 1.4$, $-2.1,0.1 ;-2.4, \pm 1.0,-3.0,0.05$.

Each injection was made gradually over a $4 \mathrm{~min}$ period, following which the needle was left in situ for a further 4 min before being withdrawn. At the completion of all surgeries the skin was sutured and an antibiotic powder (Acramide, Dales Pharmaceuticals, Skipton, UK) was applied. All rats also received a $5 \mathrm{ml}$ s.c. injection of glucose saline.

\section{Behavioral training}

Animals in the experimental condition were trained to run in the maze using a standard working memory procedure (Olton et al., 1978). Thus, at the start of a 'run' all eight arms were baited with a single food pellet (45 mg; Noyes Purified Rodent Diet, Lancaster, $\mathrm{NH}, \mathrm{USA}$ ). When the rat returned to the central platform all doors were closed for about $5 \mathrm{~s}$ before they were again opened, permitting the animal to make a choice. This continued until all eight arms had been visited. Retrieving all eight pellets constituted a single 'run,' composed of a minimum of eight arm choices. Training consisted of eight sessions. The only noteworthy aspect of the training was that each session consisted of multiple runs in the radial-arm maze, one after the other, so that each session lasted for $30 \mathrm{~min}$. Therefore, after entering all eight arms the animals were removed from the maze while it was rebaited and then returned to the maze to perform a new trial. This was repeated for $30 \mathrm{~min}$. The delay between each trial $(2 \mathrm{~min})$ was the time it took to rebait all of the arms, and during this period the animals were placed back in their home cage.

Final session: The final (eighth) session was the same as those in training, i.e. 30 min of radial-arm maze testing (approximately five radial-arm maze runs). Immediately before every session, including the final session, each animal was placed in a sound-proof box in a dark, quiet room for $30 \mathrm{~min}$. At the completion of every session, including the final session, each animal was returned to this box for 90 min prior to perfusion. This quiet period was to minimize c-fos and zif268 activation in the periods before and after the radial-arm maze task. In contrast, the home-cage control animals were taken straight from their cage and then perfused.

\section{Immunohistochemistry}

Ninety minutes after completing the final radial-arm maze session rats were deeply anesthetized with pentobarbitone sodium (1 mg/ $\mathrm{kg}$ ) and perfused transcardially with $0.1 \mathrm{M}$ phosphate-buffered saline (PBS) followed by $4 \%$ paraformaldehyde in $0.1 \mathrm{M}$ PBS. The brains were removed and postfixed in $4 \%$ paraformaldehyde for $4 \mathrm{~h}$ and then transferred to $30 \%$ sucrose overnight. Coronal sections were cut at $40 \mu \mathrm{m}$ on a freezing microtome. Two series of sections were collected in $0.1 \mathrm{M}$ PBS containing $0.2 \%$ Triton X-100 (PBST). A peroxidase block was then carried out where the sections were transferred to $0.3 \%$ hydrogen peroxide in PBST for $10 \mathrm{~min}$ to inhibit endogenous peroxidase and then washed several times with PBST. Sections were incubated in PBST containing Fos rabbit polyclonal antibody (1:5000; Ab-5, Oncogene Science, UK) or zif268 (antibody 1:3000; Egr-1 (C-19), Santa Cruz Biotechnology, USA) for $48 \mathrm{~h}$ at $4{ }^{\circ} \mathrm{C}$ with periodic rotation. Sections were then washed with PBST and incubated in biotinylated goat anti- 
rabbit secondary antibody (diluted 1:200 in PBST; Vectastain, Vector Laboratories, Burlingame, USA) and $1.5 \%$ normal goat serum for $2 \mathrm{~h}$ at room temperature on a rotator. Sections were then washed and processed with avidin-biotinylated horseradish peroxidase complex in PBST (Elite Kit; Vector Laboratories) for $1 \mathrm{~h}$ at room temperature, again with constant rotation. Sections were washed again in PBST and then in $0.05 \mathrm{M}$ Tris buffer. The reaction was then visualized using diaminobenzidine (DAB Substrate Kit, Vector Laboratories). The reaction was stopped by washing in cold PBS. Sections were mounted on gelatin-coated slides, dehydrated through a graded series of alcohols and coverslipped. An additional one-in-four series of sections was mounted directly onto slides and stained using Cresyl Violet, a Nissl stain.

\section{IEG cell counting}

Sections were scanned using a Leitz Dialux 20 microscope equipped with a Dage MTI CCD72S camera interfaced to a PC computer. After image processing, counts of the stained nuclei were carried out using the public domain Scion Image 4.0 program. Cortical areas were assessed using counts of nuclei labeled above threshold, and were taken across all layers of cortical regions. The threshold was set at the same level for both hemispheres of each section sampled. This threshold level was always set using a standard formula derived from the overall level of illumination of the region to be counted and the variance of that illumination, that is the mean $+3 \times$ standard deviation of the gray values of that section. This meant that different observers could arrive at identical counts for the same tissue, so ensuring an objective measure. Counts were made in a standard frame sample area $(0.84 \times 0.63 \mathrm{~mm})$ using a $\times 10$ objective and the camera was positioned so that the counts were taken across all cortical layers. A stereological procedure was not used as the primary goal was to compare cell counts within animals, but not to produce absolute counts. The only exception concerned the comparisons between home-cage and experimental animals that were used to established the effectiveness of the behavioral procedure in activating the system under investigation.

For all brain areas analyzed (Fig. 1), counts were taken from between two and four consecutive sections from each hemisphere (lesioned and intact side). The means of these counts were then averaged. For statistical purposes the mean count for each site in two hemispheres for each individual rat was also normalized by dividing the scores from one hemisphere by the sum from both hemispheres and the result expressed as a percentage. Thus, all pairs of normalized scores sum to 100 . The normalization procedure equates the cell counts from different regions, which would otherwise vary considerably. These normalized data were then used for those statistical analyses comparing the intact with the lesion hemispheres. The separate groups of regions were analyzed in overall analyses of variance with two factors: hemisphere and brain region. When appropriate, the simple effects for each brain region were analyzed as recommended by Winer (1971).

\section{Regions of interest}

Cytoarchitectonic subfields were identified from coronal sections (Paxinos and Watson, 1997), using the nomenclature of Swanson (1992). Regions analyzed are depicted in Fig. 1, and their abbreviations are given in Table 1. Sites were selected either because they had previously been implicated in memory processes or because they served as comparison or control regions. All of the sites from which it was decided a priori to count IEG-positive cells are presented.

IEG-reactive cells were counted in the parahippocampal region (Witter et al., 1989; Burwell et al., 1995). The perirhinal counts involved both areas 35 and 36 (Burwell et al., 1995), while the postrhinal cortex only involved cortex posterior to the perirhinal

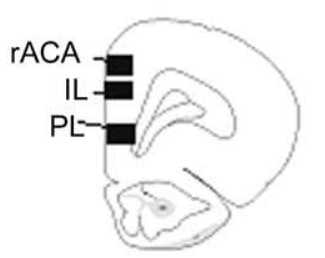

$+3.60$
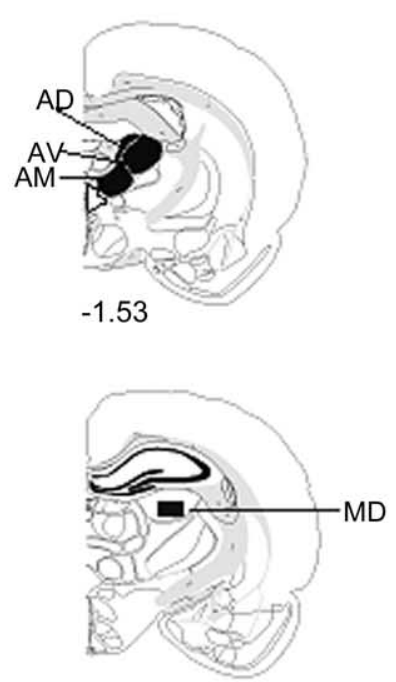

$-2.85$

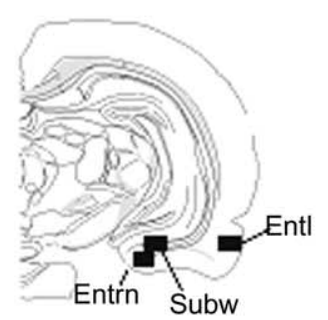

$-5.25$

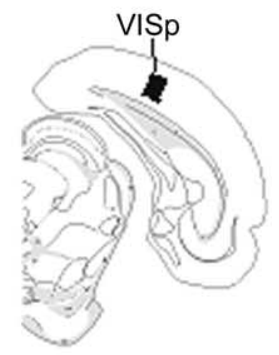

$-7.10$

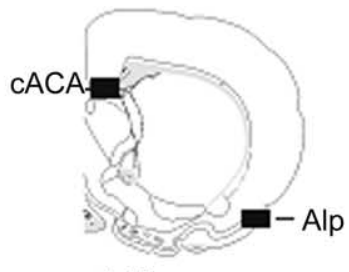

$+1.45$

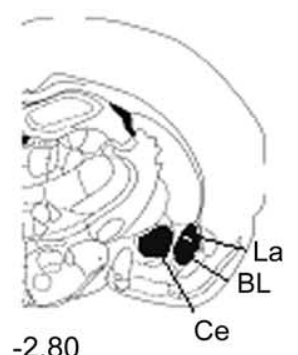

$-2.80$

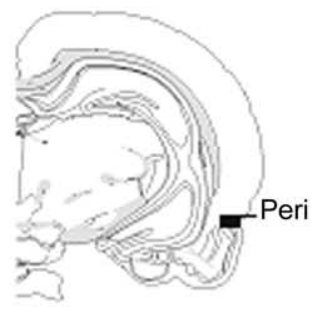

$-4.60$

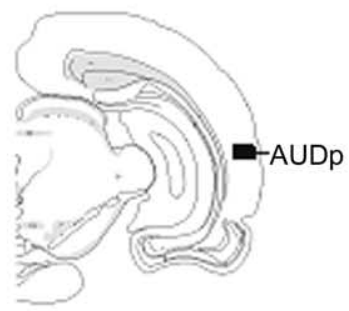

$-6.06$

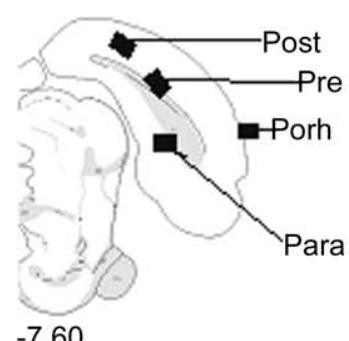

$-7.60$
Fig. 1. Diagrams of coronal sections indicating areas investigated. The numbers indicate the distance (in millimeters) of the section from bregma (Swanson, 1992). See Table 1 for list of abbreviations.

cortex and dorsal to the rhinal sulcus (Burwell and Amaral, 1998) corresponding to the ectorhinal area in Swanson (1992). The lateral and medial entorhinal cortices were considered separately in light of their different connection patterns (Witter et al., 1989; Naber et al., 1997). Separate counts were also taken from the ventral subiculum, and the pre-, post-, and parasubicular regions (Fig. 1). 
Table 1. Abbreviations of brain regions used in figures and tables

\begin{tabular}{ll}
\hline Abbreviation & Brain region \\
\hline Sensory cortical regions & \\
Alp & Primary insular cortex \\
AUDp & Primary auditory area \\
VISp & Primary visual area \\
Subicular cortices & \\
Subv & Ventral subiculum \\
Post & Postsubiculum \\
Pre & Presubiculum \\
Para & Parasubiculum \\
Cingulate cortices & \\
PL & Prelimbic cortex \\
IL & Infralimbic cortex \\
rACA & Rostral anterior cingulate cortex \\
CACA & Caudal anterior cingulate cortex \\
Parahippocampal cortices & \\
ENT1 & Lateral entorhinal cortex \\
ENTm & Medial entorhinal cortex \\
Porh & Postrhinal cortex \\
Peri & Perirhinal cortex \\
Thalamic nuclei & \\
AD & Anterior dorsal thalmic nucleus \\
AV & Anterior ventral thalamic \\
AM & nucleus \\
MD & Anterior medial thalamic \\
Amygdala nuclei & nucleus \\
BL & Mediodorsal thalamic nucleus \\
Ce & \\
La & Basolateral \\
\hline & Central \\
& Lateral \\
\hline
\end{tabular}

Cortical counts were taken from the prelimbic and infralimbic areas, as well as the rostral and caudal levels of the anterior cingulate cortex, as these regions receive inputs from the subiculum (Amaral and Witter, 1995). The retrosplenial cortex was not included in this study as previous experiments (Jenkins et al., 2004) have shown that specific laminae within particular subregions of the retrosplenial cortex may be especially sensitive to limbic damage, and so a more detailed analysis of this region will be reported elsewhere. Cell counts were also taken from the three anterior thalamic nuclei [the anterodorsal (AD), anteroventral (AV), and anteromedial (AM) nuclei], as well as the mediodorsal thalamic nucleus (MD). The mammillary bodies were not included as this structure expresses both IEGs at extremely low levels. Three different nuclei within the amygdala were also investigated; the lateral ( $\mathrm{La})$, central $(\mathrm{Ce})$ and basolateral $(\mathrm{BL})$ nuclei. All three receive direct inputs from the hippocampus (Pitkanen, 2000).

Cell counts were also taken from a number of cortical sensory regions. These regions, which comprised the visual cortex (primary visual area, VISp), the auditory cortex (primary auditory area, AUDp), and the insular cortex (Alp), were chosen in order to see how widespread the consequences of hippocampal cell loss might be.

\section{RESULTS}

\section{Hippocampal lesions}

The NMDA injections created extensive regions of cell loss (Fig. 2) within the hippocampus that did not cross over into the opposite hemisphere. Of the 15 rats with hippocampal lesions, three were discarded from the analyses as two had additional thalamic damage while another had an unexpected degree of hippocampal sparing. This left eight rats in the main experimental group, and four in the cage control group. There was no discernable difference in the lesion extent and locus in these two groups, and the cases from the experimental group with the largest and smallest lesions are depicted in Fig. 2. Three features of the lesions are especially relevant. The first is that the use of an excitotoxin resulted in sparing of the fimbria and fornix (Fig. 3). The second is that the lesions removed almost all of the cell bodies in the dentate gyrus, and CA fields 1-4, the only sparing being found in the most ventral parts of the hippocampus and the very caudal dentate gyrus (Figs. 2, 3). In all animals the dorsal subiculum was involved in the lesion, but the ventral subiculum, parasubiculum, and presubiculum were always spared. This pattern of hippocampal damage was repeated in the four home-cage baseline cases. Of the eight animals in the experimental group there was very minor cell loss in the most rostrodorsal part of the postsubiculum in three cases. The third feature is that there was both cortical thinning and cortical loss in the tissue through which the injections were made. The cortical damage was typically restricted to a small part of the parietal cortex lying dorsal to CA1 (five cases; see Fig. 3) but in two cases the cell damage included the very rostral part of the secondary visual cortex. In one case (largest lesion in Fig. 2), the extent of cortical damage was appreciably greater in both of these areas and extended into somatosensory cortex.

\section{Behavioral results}

On the final test day, the animals performed the standard version of the eight-arm radial maze. Testing took place over a 30 min session, and animals completed an average of five runs (each run comprised the retrieval of all eight pellets) in this session. The mean number of errors per run across all runs within this session ( \pm standard error of means in parentheses) was 1.55 (0.36). The mean number of correct responses in the first eight choices, across all trials in the final session, was $7.1(0.17)$.

\section{IEG counts}

The initial analyses compared the raw scores for Fos and zif 268 between the control hemispheres of the experimental and home-cage control animals. This series of $t$-tests helped to determine whether the radial-arm maze task led to an increase in IEG activity from baseline levels. A parallel set of comparisons was used for the lesioned hemispheres. As the main purpose was to determine if floor effects could have obscured a lesion effect the emphasis was on avoiding type 2 errors, and so multiple $t$-tests were appropriate. The main part of the study concerned the comparisons between the intact and lesioned hemispheres in the animals from the radial-arm maze group. The counts for each site have been grouped by region prior to analysis, so reducing type 1 errors. Comparable comparisons are not presented for the home cage group as the smaller group size $(n=4)$ makes it prone to type 2 errors. 

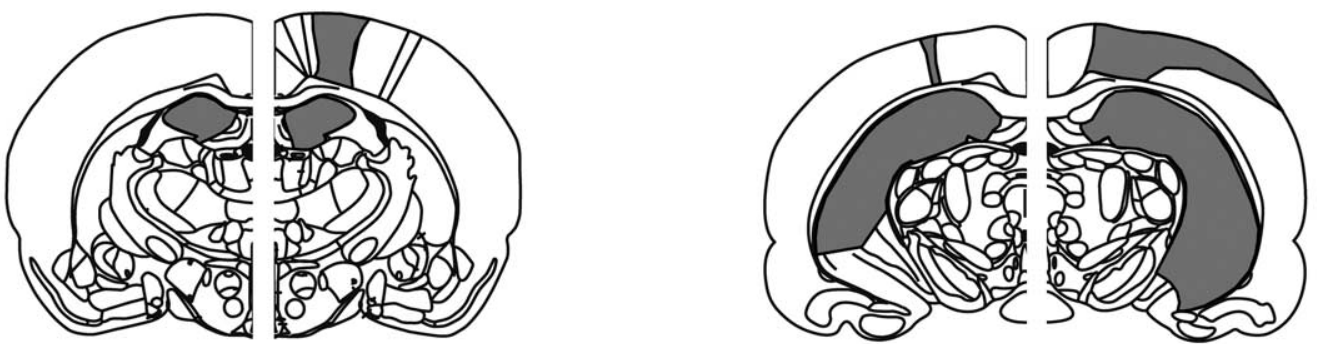

$-3.14$
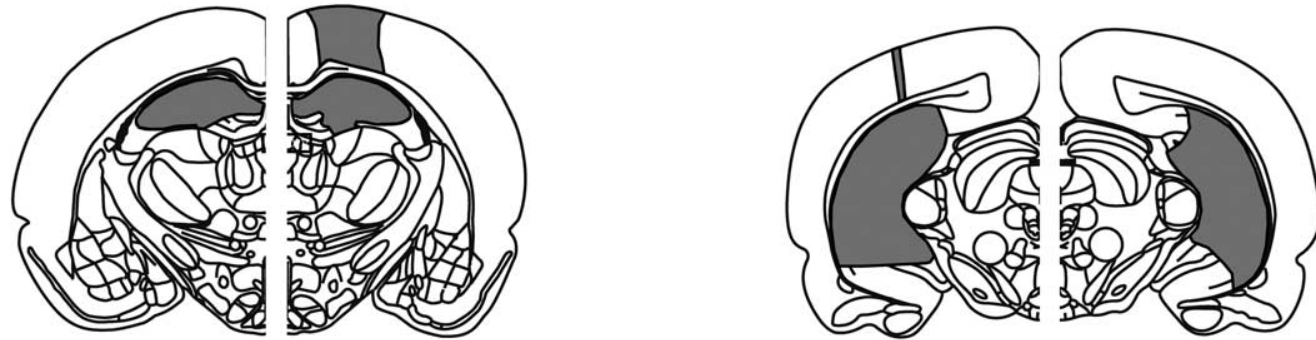

$-6.04$

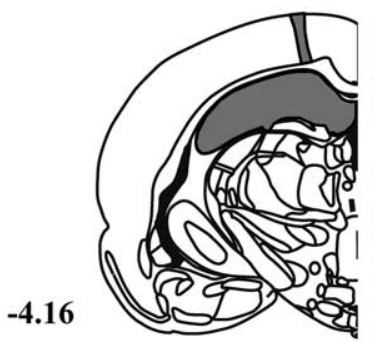

Smallest

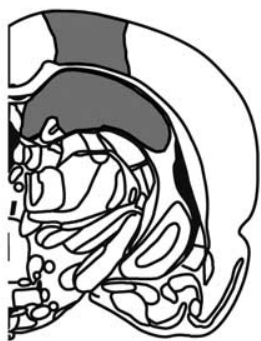

Largest

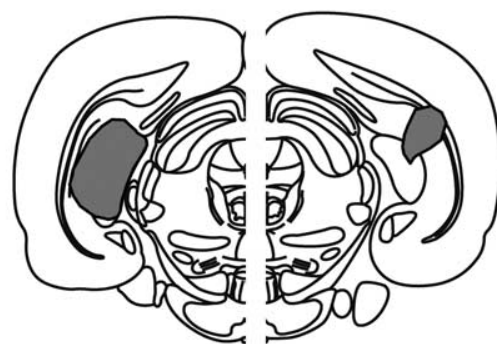

Smallest

Largest

Fig. 2. Series of coronal sections showing the area of cell loss in the smallest (left) and largest (right) hippocampal lesions. Numbers refer to the distance in millimeters from bregma (Paxinos and Watson, 1997).

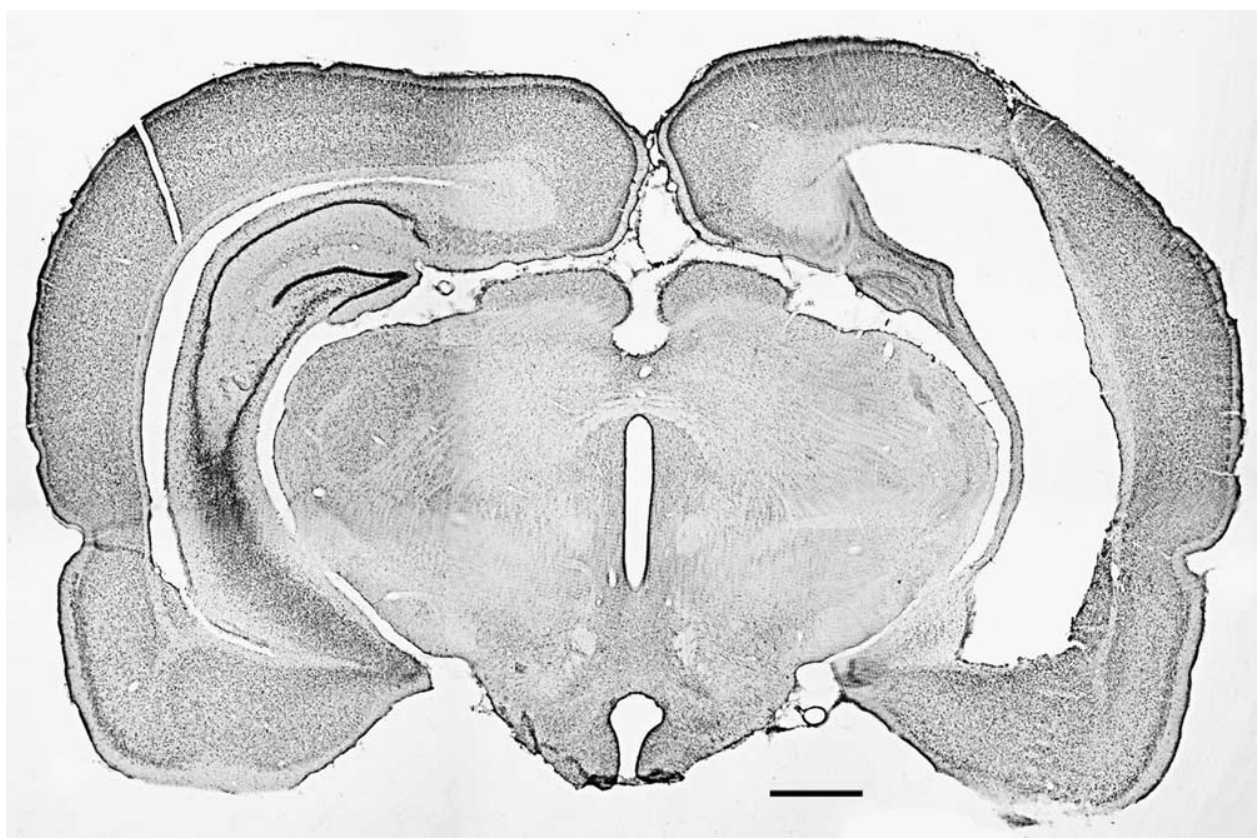

Fig. 3. Photomicrograph of a Nissl-stained coronal section showing a unilateral hippocampal lesion. Scale bar=1 mm. 
Table 2. Fos, mean raw scores ( \pm standard error)

\begin{tabular}{|c|c|c|c|c|}
\hline & \multicolumn{2}{|l|}{ Experimental } & \multicolumn{2}{|l|}{ Baseline } \\
\hline & Lesion & Control & Lesion & Control \\
\hline \multicolumn{5}{|c|}{ Sensory cortices } \\
\hline Alp & $75.8 \pm 6.8$ & $77.1 \pm 6.5$ & $57.8 \pm 3.5$ & $43.8 \pm 8.2$ \\
\hline AUDp & $71.4 \pm 12.2$ & $90.6 \pm 16.9$ & $39.0 \pm 15.0$ & $36.3 \pm 17.8$ \\
\hline VISp & $132.2 \pm 29.1$ & $147.8 \pm 33.7$ & $44.9 \pm 18.3$ & $56.6 \pm 16.9$ \\
\hline \multicolumn{5}{|c|}{ Subicular cortices } \\
\hline Subv & $59.1 \pm 11.5$ & $74.0 \pm 16.8$ & $32.2 \pm 22.8$ & $27.0 \pm 17.4$ \\
\hline Post & $123.3 \pm 23.3$ & $151.0 \pm 14.6$ & $32.3 \pm 6.8$ & $49.0 \pm 8.4$ \\
\hline Pre & $81.0 \pm 16.7$ & $110.9 \pm 17.3$ & $22.7 \pm 8.2$ & $32.7 \pm 5.6$ \\
\hline Para & $70.5 \pm 15.3$ & $75.2 \pm 10.6$ & $10.9 \pm 4.6$ & $18.8 \pm 5.2$ \\
\hline \multicolumn{5}{|c|}{ Cingulate/frontal } \\
\hline IL & $487.6 \pm 48.7$ & $512.2 \pm 46.7$ & $416.8 \pm 48.5$ & $373.1 \pm 30.2$ \\
\hline PL & $133.6 \pm 18.9$ & $144.1 \pm 15.1$ & $69.4 \pm 21.2$ & $63.5 \pm 19.8$ \\
\hline rACA & $105.5 \pm 17.3$ & $122.3 \pm 21.4$ & $56.6 \pm 21.0$ & $54.1 \pm 21.0$ \\
\hline cACA & $153.2 \pm 21.3$ & $167.7 \pm 22.6$ & $67.3 \pm 21.0$ & $86.2 \pm 30.1$ \\
\hline \multicolumn{5}{|c|}{ Parahippocampal } \\
\hline ENTI & $69.5 \pm 15.6$ & $89.5 \pm 20.1$ & $18.9 \pm 5.3$ & $18.8 \pm 7.1$ \\
\hline ENTm & $56.1 \pm 11.4$ & $71.8 \pm 10.7$ & $12.7 \pm 5.4$ & $17.3 \pm 10.3$ \\
\hline Porh & $60.6 \pm 11.5$ & $78.2 \pm 9.8$ & $18.8 \pm 4.1$ & $21.8 \pm 3.3$ \\
\hline Peri & $65.5 \pm 10.8$ & $82.5 \pm 16.8$ & $29.2 \pm 14.1$ & $44.7 \pm 25.2$ \\
\hline \multicolumn{5}{|c|}{ Thalamic nuclei } \\
\hline$A D$ & $5.2 \pm 0.9$ & $16.5 \pm 3.2$ & $6.8 \pm 2.2$ & $10.0 \pm 2.6$ \\
\hline AV & $12.1 \pm 1.9$ & $23.2 \pm 4.7$ & $9.2 \pm 6.1$ & $12.0 \pm 5.2$ \\
\hline AM & $13.8 \pm 2.5$ & $24.8 \pm 4.9$ & $16.7 \pm 8.0$ & $10.3 \pm 5.6$ \\
\hline$M D$ & $71.9 \pm 11.5$ & $84.4 \pm 13.3$ & $41.2 \pm 11.9$ & $47.6 \pm 7.2$ \\
\hline \multicolumn{5}{|c|}{ Amygdala nuclei } \\
\hline$B L$ & $97.9 \pm 6.8$ & $87.0 \pm 8.4$ & $148.3 \pm 34.6$ & $123.3 \pm 30.1$ \\
\hline $\mathrm{Ce}$ & $39.8 \pm 4.1$ & $38.6 \pm 3.4$ & $53.9 \pm 15.2$ & $38.3 \pm 4.9$ \\
\hline $\mathrm{La}$ & $3.2 \pm 1.1$ & $4.1 \pm 1.9$ & $9.6 \pm 4.7$ & $10.6 \pm 7.4$ \\
\hline
\end{tabular}

\section{Experimental versus home-cage conditions}

It was expected that IEG levels would be higher in many sites in the experimental group (Vann et al., 2000a, b). A series of $t$-tests (one-tailed) using the raw counts from the control hemispheres of both groups (Tables 2 and 3) confirmed that 13 sites showed a significant increase for Fos and 12 sites for zif268 in the radial-arm maze group (Table 4). None showed a significant decrease. The only sites not showing a significant increase for either Fos or zif268 were from the thalamus (AV, AM, MD) and the amygdala (BL, $\mathrm{La})$. The results for the lesioned hemispheres were less consistent, although a total of 12 and seven sites, respectively, showed increased Fos or zif268 counts. All four thalamic nuclei failed to show a change in either Fos or zif268 counts between the home cage controls and the experimental group for the lesioned hemisphere, along with the ventral subiculum, infralimbic cortex, rostral anterior cingulate cortex, and the central nucleus of the amygdala.

\section{Lesion versus 'normal' hemisphere}

Cingulate and parahippocampal cortices. Fos. Counts were taken in the prelimbic cortex, infralimbic cortex and anterior cingulate area, lateral and medial entorhinal cortex, perirhinal and postrhinal cortex. Overall, a significant hemispheric effect was observed $\left(F_{(1,14)}=45.8 ; P<0.0001\right)$. In- spection of simple effects revealed significant reductions in Fos levels on the lesioned side in the lateral entorhinal $\left(F_{(1,96)}=14.0 ; P<0.001\right)$, medial entorhinal $\left(F_{(1,96)}=19.5\right.$; $P<0.001)$, perirhinal $\left(F_{(1,96)}=5.56 ; P<0.05\right)$, and postrhinal cortices $\left(F_{(1,96)}=21.7 ; P<0.001\right)$ (Fig. 4A).

zif268. Like Fos, highly significant hemispheric differences were observed $\left(F_{(1,14)}=19.7 ; P<0.001\right)$. Post hoc analysis revealed a reduction in zif268 levels on the lesioned side in the lateral entorhinal $\left(F_{(1,98)}=5.9\right.$; $P<0.05)$, medial entorhinal $\left(F_{(1,98)}=25.8 ; \quad P<0.001\right)$, perirhinal $\left(F_{(1,98)}=5.7 ; P<0.05\right)$, and postrhinal cortices $\left(F_{(1,98)}=7.8 ; P<0.01\right)$ (Fig. 4B).

Cortical sensory regions. Fos. The cortical sensory regions examined were the primary visual, auditory and insular cortices. Across the three cortical areas a significant hemispheric effect was observed $\left(F_{(1,14)}=24.4\right.$; $P<0.001)$. Simple effects analysis showed a significant decrease in Fos levels on the lesioned side in the auditory $\left(F_{(1,42)}=26.2 ; P<0.001\right)$ and visual cortex $\left(F_{(1,42)}=6.4\right.$; $P<0.05)$. No significant difference was observed in the Alp (Fig. 5A).

zif268. Across the three regions examined VISp, AUDp, and Alp there was no significant hemisphere effect $(F<1)$. A hemisphere $\times$ area interaction, however, was observed $\left(F_{(2,28)}=3.6, \quad P<0.05\right)$. Simple effects analysis 
Table 3. zif 268, Mean raw scores ( \pm standard error)

\begin{tabular}{|c|c|c|c|c|}
\hline & \multicolumn{2}{|l|}{ Experimental } & \multicolumn{2}{|l|}{ Baseline } \\
\hline & Lesion & Control & Lesion & Control \\
\hline \multicolumn{5}{|c|}{ Sensory cortices } \\
\hline Alp & $240.7 \pm 22.9$ & $208.0 \pm 17.7$ & $172.0 \pm 16.2$ & $172.9 \pm 31.1$ \\
\hline AUDp & $305.2 \pm 37.7$ & $332.6 \pm 32.1$ & $173.4 \pm 47.9$ & $184.5 \pm 29.8$ \\
\hline VISp & $354.7 \pm 48.3$ & $354.1 \pm 50.6$ & $256.9 \pm 91.3$ & $241.0 \pm 68.9$ \\
\hline \multicolumn{5}{|c|}{ Subicular cortices } \\
\hline Subv & $81.7 \pm 16.6$ & $105.7 \pm 14.0$ & $70.6 \pm 29.4$ & $63.4 \pm 13.3$ \\
\hline Post & $253.9 \pm 38.0$ & $310.0 \pm 41.9$ & $152.3 \pm 30.9$ & $182.3 \pm 25.1$ \\
\hline Pre & $162.7 \pm 27.9$ & $209.8 \pm 30.8$ & $105.5 \pm 6.7$ & $114.3 \pm 25.1$ \\
\hline Para & $109.1 \pm 19.2$ & $145.4 \pm 19.5$ & $58.0 \pm 13.7$ & $40.4 \pm 6.5$ \\
\hline \multicolumn{5}{|c|}{ Cingulate/frontal } \\
\hline IL & $545.9 \pm 44.3$ & $555.7 \pm 41.8$ & $518.6 \pm 26.6$ & $516.9 \pm 38.5$ \\
\hline $\mathrm{PL}$ & $316.1 \pm 47.2$ & $305.5 \pm 48.2$ & $166.8 \pm 32.2$ & $178.5 \pm 28.3$ \\
\hline rACA & $335.6 \pm 39.5$ & $367.7 \pm 42.3$ & $228.2 \pm 50.7$ & $211.8 \pm 49.0$ \\
\hline cACA & $443.6 \pm 51.9$ & $459.7 \pm 57.7$ & $219.8 \pm 37.0$ & $217.9 \pm 41.1$ \\
\hline \multicolumn{5}{|c|}{ Parahippocampal } \\
\hline ENTI & $183.6 \pm 27.8$ & $208.9 \pm 22.4$ & $91.4 \pm 21.4$ & $90.9 \pm 24.6$ \\
\hline ENTm & $118.0 \pm 33.9$ & $146.4 \pm 34.7$ & $47.4 \pm 3.8$ & $58.5 \pm 5.5$ \\
\hline Porh & $176.5 \pm 40.5$ & $198.8 \pm 36.1$ & $117.0 \pm 36.1$ & $127.9 \pm 26.4$ \\
\hline Peri & $161.4 \pm 16.9$ & $191.8 \pm 17.5$ & $92.6 \pm 20.5$ & $108.0 \pm 27.2$ \\
\hline \multicolumn{5}{|c|}{ Thalamic nuclei } \\
\hline$A D$ & $6.4 \pm 1.8$ & $10.9 \pm 1.5$ & $10.8 \pm 4.4$ & $27.3 \pm 15.7$ \\
\hline $\mathrm{AV}$ & $13.3 \pm 4.0$ & $20.2 \pm 3.3$ & $12.8 \pm 6.3$ & $10.2 \pm 0.8$ \\
\hline AM & $21.4 \pm 5.1$ & $28.8 \pm 6.4$ & $11.0 \pm 5.1$ & $8.7 \pm 5.3$ \\
\hline$M D$ & $60.3 \pm 9.6$ & $76.5 \pm 13.4$ & $65.0 \pm 23.9$ & $67.8 \pm 27.5$ \\
\hline \multicolumn{5}{|c|}{ Amygdala nuclei } \\
\hline $\mathrm{BL}$ & $195.6 \pm 9.8$ & $198.8 \pm 15.8$ & $248.4 \pm 33.3$ & $199.8 \pm 30.5$ \\
\hline $\mathrm{Ce}$ & $81.3 \pm 7.1$ & $63.5 \pm 7.3$ & $90.9 \pm 2.7$ & $94.4 \pm 7.3$ \\
\hline La & $40.2 \pm 3.5$ & $40.6 \pm 3.0$ & $51.3 \pm 7.6$ & $41.3 \pm 6.3$ \\
\hline
\end{tabular}

showed a significant increase in zif268 levels on the lesioned side in the Alp $\left(F_{(1,42)}=4.7 ; P<0.05\right)$ (Fig. 5B).

Thalamic nuclei. Fos. The thalamic regions examined were $A D, A V, A M$ and $M D$. Overall, a significant hemispheric effect $\left(F_{(1,14)}=90.9, P<0.001\right)$, and hemisphere by area interaction $\left(F_{(3,42)}=9.74, P<0.001\right)$ was observed. Post hoc analysis revealed significant decreases in Fos levels in the lesioned hemisphere of $A D$ $\left(F_{(1,56)}=83.4 ; P<0.001\right), \mathrm{AV}\left(F_{(1,56)}=23.7 ; P<0.001\right)$, and AM $\left(F_{(1,56)}=20.0 ; P<0.001\right)$. MD levels were not significantly different between lesioned and control sides $\left(F_{(1,56)}=3.0 ; P>0.05\right)$ (Fig. 6A).

zif 268. Examination of the four thalamic regions $A D$, $\mathrm{AV}, \mathrm{AM}$ and $\mathrm{MD}$ revealed a significant hemispheric effect $\left(F_{(1,14)}=23.62, P<0.001\right)$, with a significant hemisphere by area interaction $\left(F_{(3,42)}=9.1, P=0.0001\right)$. Analysis of simple effects revealed a reduction in zif268 levels on the lesioned side compared with the intact side in $A D$ $\left(F_{(1,28)}=37.7, P<0.001\right), \mathrm{AV}\left(F_{(1,28)}=26.9, P<0.001\right)$, and AM $\left(F_{(1,28)}=7.4, P<0.05\right)$. MD levels did not differ significantly between the two hemispheres $\left(F_{(1,28)}=4.1 ; P>0.05\right)$ (Fig. 6B).

Amygdala nuclei. Fos. There was no significant hemispheric effect for the three nuclei $\left(F_{(1,14)}=1.2\right.$, $P=0.29$ or hemisphere by area interaction $(F<1)$ (Fig. 7A). zif268. Examination of the three amygdala nuclei revealed no significant hemispheric effect $\left(F_{(1,14)}=1.8\right.$, $P=0.21)$. A hemisphere by area interaction, however, was observed $\left(F_{(2,28)}=5.0, P<0.05\right)$. Simple effects analysis showed a significant increase in zif268 levels on the lesioned side in the central nucleus $\left(F_{(1,36)}=9.8 ; P<0.01\right)$ (Fig. 7B).

Subicular cortices. Fos. Counts from the various subicular cortices revealed a significant hemispheric effect $\left(F_{(1,14)}=15.0, P<0.01\right)$, but no significant area by hemisphere interaction $\left(F_{(3,42)}=1.3, P=0.28\right)$. Significant reductions in Fos levels were observed on the lesioned side in the postsubiculum $\left(F_{(1,47)}=7.9, P<0.01\right)$ and presubiculum $\left(F_{(1,47)}=15.0, P<0.001\right)$ (Fig. 8A).

zif268. There was a significant hemispheric effect $\left(F_{(1,14)}=11.5, P<0.01\right)$, but no significant area by hemisphere interaction $(F<1)$. Significant reduction in IEG levels was observed on the lesioned side compared with the intact side in the ventral subiculum $\left(F_{(1,35)}=9.1, P<0.01\right)$, presubiculum $\left(F_{(1,35)}=6.4, P<0.05\right)$ and parasubiculum $\left(F_{(1,35)}=8.7, P<0.01\right)$ (Fig. 8B).

\section{DISCUSSION}

This study used IEG expression as a marker of neuronal activation to compare activity levels across hemispheres in 
Table 4. Summary of significant changes in immediate early gene protein counts for the experimental group (radial-arm maze) compared with the home-cage controls

\begin{tabular}{|c|c|c|c|c|}
\hline & \multicolumn{2}{|c|}{ Control hemisphere } & \multicolumn{2}{|c|}{ Lesion hemisphere } \\
\hline & Fos & Zif268 & Fos & Zif268 \\
\hline Alp & $\uparrow \uparrow$ & - & - & $\uparrow$ \\
\hline AUDp & $\uparrow$ & $\uparrow \uparrow$ & - & $\uparrow$ \\
\hline VISp & $\uparrow$ & - & $\uparrow$ & - \\
\hline Subv & - & $\uparrow$ & - & - \\
\hline Post & $\uparrow \uparrow$ & $\uparrow$ & $\uparrow \uparrow$ & - \\
\hline Pre & $\uparrow \uparrow$ & $\uparrow$ & $\uparrow$ & - \\
\hline Para & $\uparrow \uparrow$ & $\uparrow \uparrow$ & $\uparrow$ & - \\
\hline IL & $\uparrow$ & - & - & - \\
\hline PL & $\uparrow \uparrow$ & - & $\uparrow$ & $\uparrow$ \\
\hline rACA & $\uparrow$ & $\uparrow$ & - & - \\
\hline cACA & $\uparrow$ & $\uparrow$ & $\uparrow$ & $\uparrow \uparrow$ \\
\hline ENTI & $\uparrow$ & $\uparrow \uparrow$ & $\uparrow$ & $\uparrow$ \\
\hline ENTm & $\uparrow \uparrow$ & - & $\uparrow$ & - \\
\hline Porh & $\uparrow$ & $\uparrow$ & $\uparrow$ & - \\
\hline Peri & - & $\uparrow$ & $\uparrow$ & $\uparrow$ \\
\hline$A D$ & - & $\uparrow$ & - & - \\
\hline AV & - & - & - & - \\
\hline AM & - & - & - & - \\
\hline MD & - & - & - & - \\
\hline $\mathrm{BL}$ & - & - & $\uparrow$ & $\uparrow$ \\
\hline $\mathrm{Ce}$ & - & $\uparrow$ & - & - \\
\hline La & - & - & $\uparrow$ & - \\
\hline
\end{tabular}

Higher counts in the experimental groups are shown by $\uparrow(P<0.05)$ and $\uparrow \uparrow(P<0.01)$ derived from multiple $t$-tests. Abbreviations as Table 1.

22 brain sites in rats with unilateral hippocampal lesions performing a spatial memory task. The task, working memory in the radial-arm maze, was selected as bilateral lesions of the hippocampal formation produce a striking deficit that is typically characterized as failure of spatial memory (Jarrard, 1978; Olton et al., 1978). The goal was to map the extent to which these lesion-induced disruptions spread beyond the hippocampus and to see if they are selective to other brain areas also thought to be critical for the performance of the same task. By using unilateral lesions the present study avoided the problem of abnormal arm choices associated with bilateral lesions, and all animals in the main experimental group performed the task at a relatively high level of accuracy. It is, however, the case that the intact hemisphere cannot be regarded as normal as it will have lost commissural inputs from the contralateral hippocampus. In addition, a smaller group of animals with unilateral hippocampal lesions was examined to help identify those sites in which the IEG differences might be task dependent for spatial memory. Comparisons with this baseline group using raw counts confirmed that the experimental condition had raised IEG expression in many sites. A significant IEG increase was not, however, a prerequisite to finding a lesion-induced change (e.g. the anterior thalamic nuclei), but inspection of the data also revealed the high levels of variance in the raw counts. This problem was solved in the main part of the study by comparing across hemispheres in the same animal.
The most striking result in the experimental group was that all of the significant changes in IEG activity reflected a relative decrease on the lesion side. As the results for the two IEGs were usually in close agreement we shall initially consider the eight sites where significant IEG decreases were found after the radial-arm maze task for both Fos and zif268. These sites consist of the lateral entorhinal cortex, medial entorhinal cortex, perirhinal cortex, postrhinal cortex, the presubiculum, and the three anterior thalamic nuclei. All eight structures fall into one of two anatomical areas, the parahippocampal region and the anterior thalamic nuclei.

The parahippocampal region, which comprises the presubiculum, parasubiculum, lateral entorhinal cortex, medial entorhinal cortex, perirhinal cortex, and postrhinal cortex (Witter and Wouterlood, 2002) is part of the higher order polymodal association cortex and is regarded as a vital stage for most of the sensory information reaching the hippocampus (dentate gyrus, CA1-4). All of the structures within the parahippocampal region, with the exception of the parasubiculum and postsubiculum, showed a significant decrease in both IEGs. The consistent changes in the entorhinal cortices were to be expected as there is

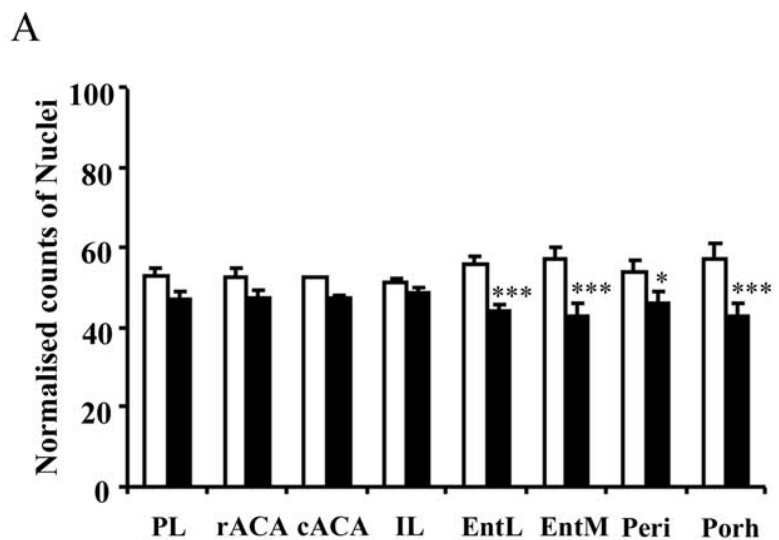

B

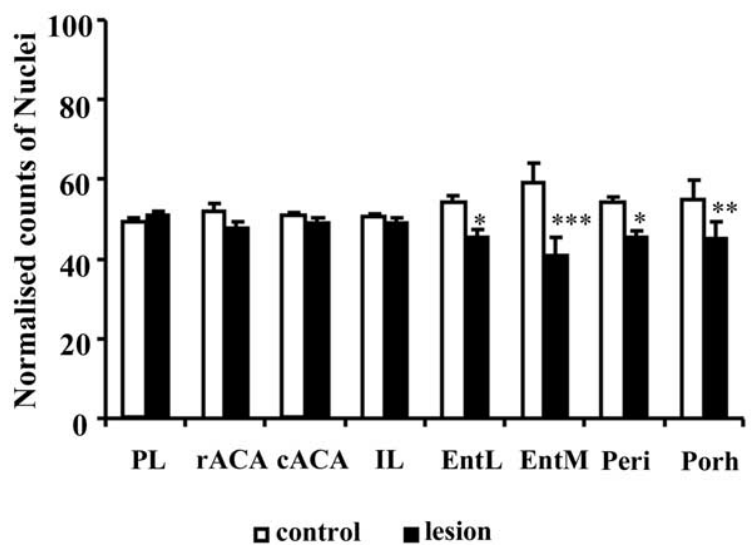

Fig. 4. Normalized counts of Fos (A) and zif268 (B) -positive nuclei in cingulate and parahippocampal regions. Data are shown as mean \pm S.E. All normalized data sum to 100 (see Experimental Procedures). See Table 1 for abbreviations. Significance of hemispheric differences in normalized counts: $* P<0.05$, *** $P<0.001$. 
A

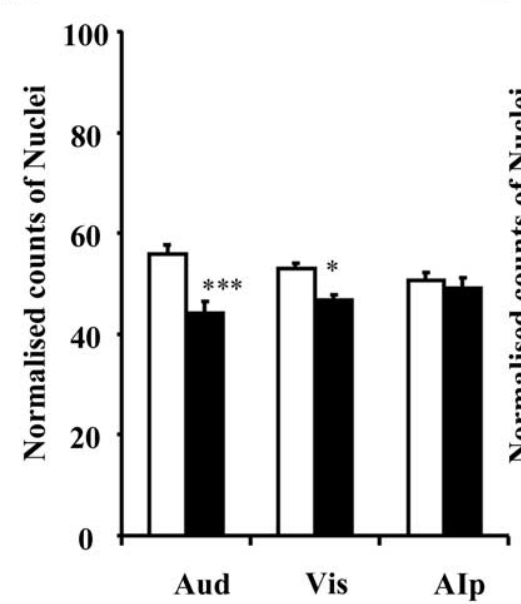

B

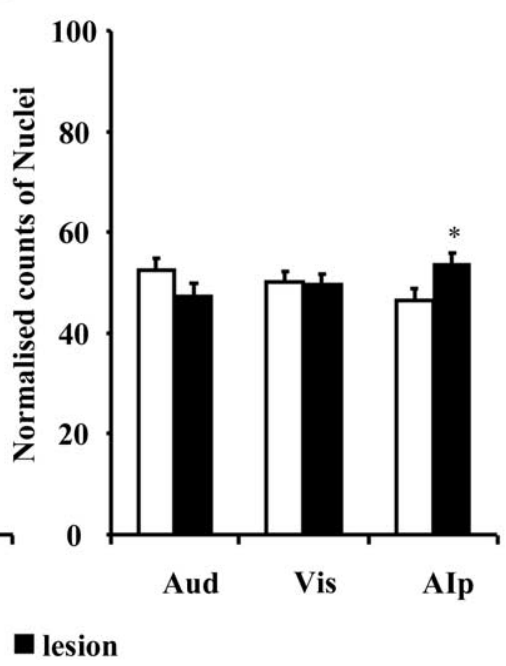

Fig. 5. Normalized counts of Fos (A) and zif268 (B) -positive nuclei in 'control' cortices. Data are shown as mean \pm S.E. All normalized data sum to 100 (see Experimental Procedures). See Table 1 for abbreviations. Significance of hemispheric differences in normalized counts: $* P<0.05$, ** $P<0.01, * * * P<0.001$.

direct evidence that the entorhinal cortex and the hippocampus work in concert to support performance of the radial-arm maze task (Olton et al., 1982). The two inconsistent parahippocampal areas showed changes in just one IEG. The parasubiculum had a significant zif268 decrease with no Fos change while the postsubiculum showed a significant decrease of Fos but no hemispheric changes in zif268 counts. Comparisons with the homecage control animals using the intact hemisphere counts also showed that the task increased parahippocampal IEG levels in all sites for at least one IEG. Significant increases were found for both IEGs in the lateral entorhinal cortex, postrhinal cortex, postsubiculum, presubiculum and parasubiculum. These results accord closely with a previous study of c-fos expression in normal rats, which also showed increased Fos levels in almost all parahippocampal structures after radial-arm maze performance but which included an additional sensorimotor control group (Vann et al., 2000a,b).

Comparisons between the home-cage and radial-arm maze animals showed that parahippocampal IEG increases were also found on the side with the hippocampal lesion. These increases were most consistently seen for Fos, and show the way in which this region is still driven by afferent, sensory information. At the same time, the significant IEG decreases across the hemispheres also help to emphasize the point that the parahippocampal cortices do not merely provide afferent sensory information to the hippocampus, they engage in a complex two-way interaction. The hippocampus has reciprocal connections not only
A

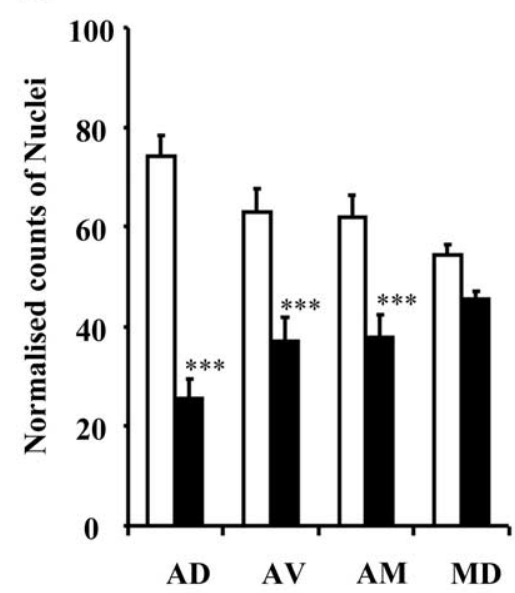

B

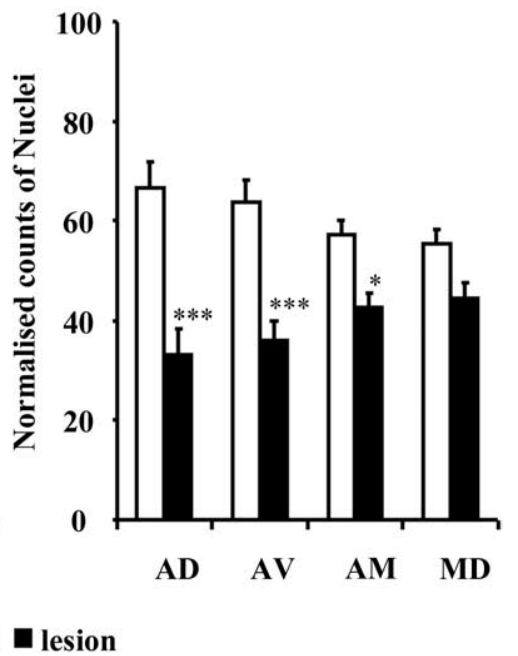

Fig. 6. Normalized counts of Fos (A) and zif268 (B) -positive nuclei in thalamic nuclei. Data are shown as mean \pm S.E.M. All normalized data sum to 100 (see Experimental Procedures). See Table 1 for abbreviations. Significance of hemispheric differences in normalized counts: $* P<0.05$, $* * * P<0.001$. 
A

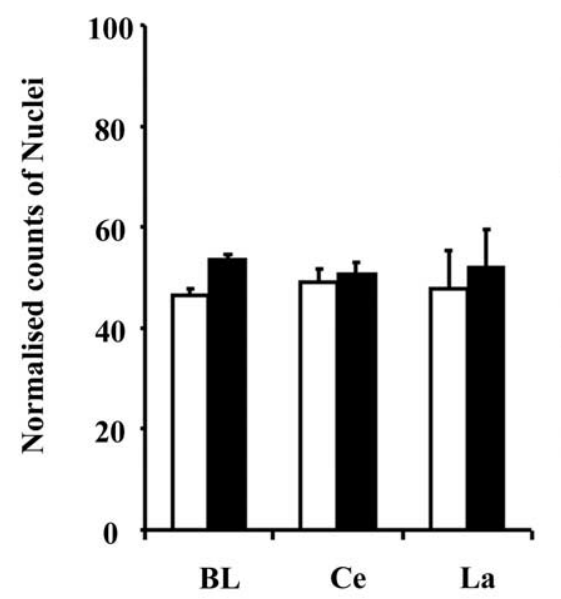

B

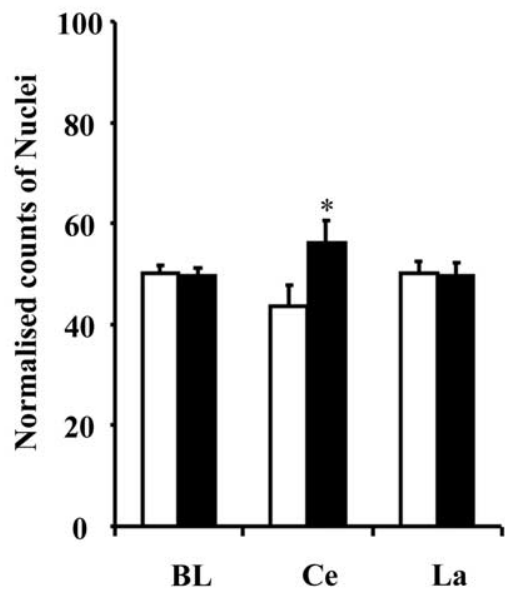

\section{$\square$ control $\square$ lesion}

Fig. 7. Normalized counts of Fos (A) and zif268 (B) -positive nuclei in amygdala nuclei. Data are shown as mean \pm S.E.M. All normalized data sum to 100 (see Experimental Procedures). See Table 1 for abbreviations.

with the entorhinal cortices (Witter et al., 1989) but also with the perirhinal and postrhinal cortices (Shi and Cassell, 1997; Burwell and Amaral, 1998). These latter connections are both direct and indirect, via the entorhinal cortex. It is presumably via the loss of these connections that many of the IEG changes occurred.

The highly consistent IEG changes in the anterior thalamic nuclei presumably reflect the loss of a number of routes by which the hippocampus can affect these thalamic nuclei. The most direct inputs are those from the subiculum and presubiculum (Meibach and Siegel, 1977), and so the involvement of the rostral dorsal subiculum in the lesions is likely to have contributed to the IEG changes. There are also a number of indirect routes linking the

A

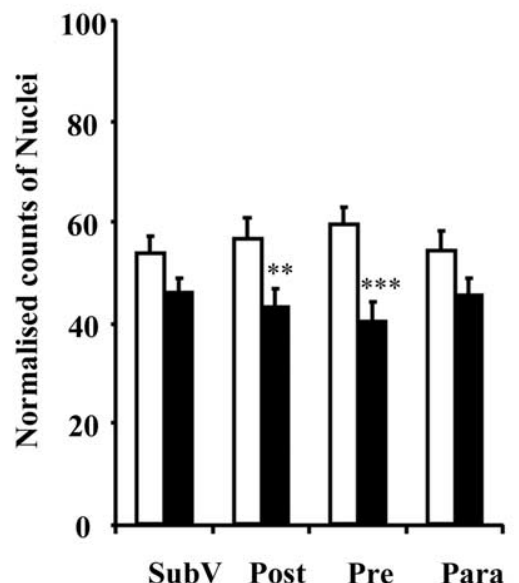

hippocampus with the anterior thalamic nuclei, of which the projections via the mammillary bodies are probably the best known. Electrophysiological studies provide further evidence for the close linkage between the hippocampus, mammillary bodies, and anterior thalamic nuclei (Blair et al., 1998; Albo et al., 2003; Vertes et al., 2004), and provide further evidence of their mutual dependence.

The marked impact of hippocampal damage on anterior thalamic IEG activity is also predicted by functional analyses using disconnection techniques. These studies have shown that the hippocampus and anterior thalamic nuclei make interdependent contributions to the radial-arm maze task (Byatt and Dalrymple-Alford, 1996; Warburton et al., 2000, 2001). It is, however, misleading to see this

B

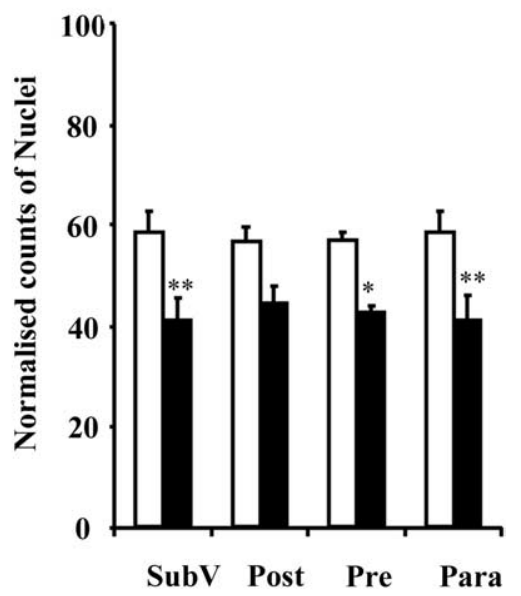

\section{$\square$ control $\square$ lesion}

Fig. 8. Normalized counts of Fos (A) and zif268 (B) -positive nuclei in subicular cortices. Data are shown as mean \pm S.E.M. All normalized data sum to 100 (see Experimental Procedures). See Table 1 for abbreviations. Significance of hemispheric differences in normalized counts: $* P<0.05$, ** $P<0.01, * * * P<0.001$. 
relationship as one way (hippocampus to anterior thalamic nuclei) as there are reciprocal connections from the anterior thalamic nuclei to the hippocampal region (Shibata, 1993a,b). Furthermore, lesions in the anterior thalamic nuclei lower Fos counts in hippocampal and parahippocampal regions (Jenkins et al., 2002a,b), while rostral thalamic damage reduces hippocampal acetylcholine release during spatial working memory task (Savage et al., 2003). This, therefore, appears to be a reciprocal relationship with both regions dependent on the other.

The close relationship between the hippocampus and the anterior thalamic nuclei can be contrasted with a different thalamic nucleus, medialis dorsalis. Although MD has often been implicated in human mnemonic processes (Van der Werf et al., 2000, 2003), its lack of IEG response to hippocampal damage can be contrasted with the anterior thalamic nuclei. Initial lesion studies in rats had appeared to show that MD damage is sufficient to impair radial-arm maze acquisition (Stokes and Best, 1988, 1990), but the adoption of cytotoxic lesion techniques and the careful avoidance of cell loss in the anterior thalamic nuclei has since shown that MD is not critical for acquisition of the standard task (Beracochea et al., 1989; Hunt and Aggleton, 1998). The present result is just one of a series of dissociations between MD and the anterior thalamic nuclei, reinforcing the view that two qualitatively different contributions to memory are provided by the hippocampal-anterior thalamic axis and the medialis dorsalisprefrontal cortex axis (Aggleton and Brown, 1999; Van der Werf et al., 2000, 2003).

Another informative list of structures comprise those that showed no hemispheric differences for either IEG following the radial-arm maze task. This list includes the prelimbic cortex, anterior cingulate cortex, infralimbic cortex, and two of the three amygdala nuclei. A remarkable feature is that all of these structures receive direct hippocampal/subicular inputs. The prelimbic cortex receives direct inputs from CA1 and the subiculum (Jay and Witter, 1991), while the subiculum projects to the other cortical sites (Amaral and Witter, 1995). The main hippocampal inputs to the amygdala nuclei originate in the subiculum, but the CA1 field and entorhinal cortex also contribute (Pitkanen, 2000). The lack of IEG changes in these sites shows that the results do not merely mirror connectivity, and suggests that the critical engagement with the hippocampus is either dependent on the type of task or the stage of learning. It is, for example, accepted that the hippocampus and amygdala make qualitatively different contributions to memory tests in the radial-arm maze (McDonald and White, 1993). The amygdala can, however, influence the consolidation of motivationally arousing training experiences (McGaugh, 2004), and the sites that it influences include the hippocampal formation (McGaugh, 2004; Packard and Wingard, 2004). The present data indicate that although there are reciprocal hippocampalamygdala connections, their mutual engagement is not obligatory. This may be because the interaction is primarily driven by the amygdala or because the present task, which involved well-trained rats in familiar conditions, is not suf- ficiently arousing (Packard and Chen, 1999). To test these notions it would be necessary to contrast the radial-arm maze task with tasks more likely to engage both regions. Examples might include contextual fear conditioning and socially transmitted food preference (Countryman et al., 2005; McGaugh, 2004).

An unexpected finding was the evidence that hippocampal lesions can affect Fos expression in cortical sensory areas such as the primary auditory and VISps. It is unlikely that these changes were a result of extrahippocampal damage, as thinning of the parietal cortex was the only common pathology. An alternative is that these changes are mediated by indirect hippocampal connections, most likely those with the entorhinal and retrosplenial cortices (Amaral and Witter, 1995). These changes in cortical sensory areas reveal how diffuse the consequences of hippocampal lesions may become and why it may be so difficult to explain their effects by reference to a unitary process.

The results of the present study can also be compared with the consequences of unilateral fornix lesions on IEG production (Vann et al., 2000c), as both studies investigated c-fos expression after performance of the same radial-arm maze task. It would be expected that the two sets of results would show much overlap. Like the hippocampus, unilateral fornix lesions produced widespread hypoactivity. Common areas of hypoactivity with the current study include the three anterior thalamic nuclei, the presubiculum, postsubiculum, the medial and lateral entorhinal cortices, and the postrhinal cortices. In the present study IEG hypoactivity was also induced in the perirhinal cortex, which was not observed after unilateral fornix lesions (Vann et al., 2000c). Conversely, unilateral fornix damage led to changes in cingulate and frontal Fos levels that were not observed after unilateral hippocampal ablation. In order to understand these differences it is important to appreciate that the hippocampal lesions spared the fimbria/fornix and so would have had a less direct effect upon those regions that send or receive inputs through this tract (e.g. the subiculum, presubiculum, parasubiculum, and entorhinal cortices).

To our knowledge this is the first study to map the consequences of hippocampal damage in this way. While previous studies on the effects of lesions in related limbic areas (Vann et al., 2000c; Jenkins et al., 2002a,b, 2004) have concentrated on c-fos, the present study also investigated zif268. It should be stressed that although these IEGs can serve as indirect markers of neuronal activity, they need not be regarded as essential for task performance (Zhang et al., 2002). Although a large number of brain sites showed evidence of IEG hypoactivity, this was not simply predicted by the existence of direct connections with the hippocampus or subiculum. At the same time, the finding that only the anterior thalamic nuclei and the parahippocampal region showed decreases for both c-fos and zif268 expression reinforces the view that these regions form an interdependent system with the hippocampus that is vital for working memory tasks in the radial-arm maze. 
Acknowledgments-This research was supported by funding from the UK Medical Research Council.

\section{REFERENCES}

Aggleton JP, Brown MW (1999) Episodic memory, amnesia, and the hippocampal-anterior thalamic axis. Behav Brain Sci 22:425-489.

Aggleton JP, Desimone R, Mishkin M (1986) The origin, course, and termination of the hippocampo-thalamic projections in the macaque. J Comp Neurol 243:409-421.

Aggleton JP, Saunders RC (1997) The relationships between temporal lobe and diencephalic structures implicated in anterograde amnesia. Memory 5:49-71.

Albo Z, Viana Di Prisco G, Vertes RP (2003) Anterior thalamic unit discharge profiles and coherence with hippocampal theta rhythm. Thalamus Relat Syst 2:133-144.

Amaral DG, Witter MP (1995) Hippocampal formation. In: The rat nervous system (Paxinos G, ed), pp 443-493. San Diego: Academic Press.

Barbizet J (1963) Defect of memorizing of hippocampal-mammillary origin: a review. J Neurol Neurosurg Psychiatry 26:127-135.

Beracochea DJ, Jaffard R, Jarrard LE (1989) Effects of anterior or dorsomedial thalamic ibotenic lesions on learning and memory in rats. Behav Neural Biol 51:364-376.

Blair HT, Cho J, Sharp PE (1998) Role of the lateral mammillary nucleus in the rat heard-direction circuit: a combined single-unit and lesion study. Neuron 21:1387-1397.

Bozon B, Davis S, Laroche S (2002) Regulated transcription of the immediate-early gene Zif268: mechanisms and gene dosage-dependent function in synaptic plasticity and memory formation. Hippocampus 12:570-577.

Burwell RD, Witter MP, Amaral DG (1995) Perirhinal and postrhinal cortices of the rat: A review of the neuroanatomical literature and comparison with findings from the monkey brain. Hippocampus 5 : 390-408.

Burwell RD, Amaral DG (1998) Cortical afferents of the perirhinal, postrhinal, and entorhinal cortices of the rat. J Comp Neurol 398: 179-205.

Byatt G, Dalrymple-Alford JC (1996) Both anteromedial and anteroventral thalamic lesions impair radial-maze learning in rats. Behav Neurosci 110:1335-1348.

Countryman RA, Orlowski JD, Brightwell JJ, Oskowitz AZ, Colombo PJ (2005) CREB phosphorylation and c-Fos expression in the hippocampus of rats during acquisition and recall of a socially transmitted food preference. Hippocampus 15:56-67.

Coutureau E, Galani R, Gosselin O, Majchrzak M, Di Scala G (1999) Entorhinal but not hippocampal or subicular lesions disrupt latent inhibition in rats. Neurobiol Learn Mem 72:143-157.

Davis S, Bozon B, Laroche S (2003) How necessary is the activation of the immediate early gene zif268 in synaptic plasticity and learning? Behav Brain Res 142:17-30.

Delay J, Brion S (1969) Le syndrome de Korsakoff. Paris: Masson.

Dragunow M, Faull R (1989) The use of c-fos as a metabolic marker in neuronal pathway tracing. J Neurosci Methods 29:261-265.

Gaffan D (1992a) The role of the hippocampus-fornix-mammillary system in episodic memory. In: Neuropsychology of memory, 2nd edition (Squire LR, Butters N, eds), pp 336-356. New York: Guilford.

Gaffan D (1992b) Amnesia for complex naturalistic scenes and for objects following fornix transaction in the rhesus monkey. Eur J Neurosci 4:381-388.

Guzowski J, Setlow B, Wagner EK, McGaugh JL (2001) Experiencedependent gene expression in the rat hippocampus after spatial learning: a comparison of the immediate-early genes Arc, c-fos, and zif268. J Neurosci 21:5089-5098.

Hall J, Thomas KL, Everitt BJ (2001) Cellular imaging of zif268 expression in the hippocampus and amygdala during contextual and cued fear memory retrieval: selective activation of hippocampal
CA1 neurons during the recall of contextual memories. J Neurosci 21:2186-2193.

He J, Yamada K, Nabeshima T (2002) A role of Fos expression in the CA3 region of the hippocampus in spatial memory formation in rats. Neuropharmacology 26:259-268.

Herdegen T, Leah JD (1998) Inducible and constitutive transcription factors in the mammalian nervous system: control of gene expression by jun, fos, and krox, and CREB/ATF proteins. Brain Res Rev 28:370-490.

Hunt PR, Aggleton JP (1998) An examination of the spatial working memory deficit following neurotoxic medial dorsal thalamic lesions in rats. Behav Brain Res 97:129-141.

Jarrard LE (1978) Selective hippocampal lesions: differential effects on performance by rats of a spatial task with preoperative versus postoperative training. J Comp Physiol Psychol 92:1119-1127.

Jay TM, Witter MP (1991) Distribution of hippocampal., CA1 and subicular efferents in the prefrontal cortex of the rat studied by means of anterograde transport of Phaseolus vulgaris-leucoagglutin. J Comp Neurol 313:574-586.

Jenkins TA, Dias R, Amin E, Brown MW, Aggleton JP (2002a) Fos imaging reveals that lesions of the anterior thalamic nuclei produce widespread limbic hypoactivity in rats. J Neurosci 22:5230-5238.

Jenkins TA, Dias R, Amin E, Aggleton JP (2002b) Changes in Fos expression in the rat brain after unilateral lesions of the anterior thalamic nuclei. Eur J Neurosci 16:1425-1432.

Jenkins TA, Vann SD, Amin E, Aggleton JP (2004) Anterior thalamic lesions stop immediate early gene activation in selective laminae of the retrosplenial cortex: evidence of covert pathology in rats. Eur J Neurosci 19:3291-3304.

Jones MW, Errington ML, French PJ, Fine A, Bliss TV, Garel S, Charney P, Bozon B, Laroche S, Davis S (2001) A requirement for the immediate early gene Zif268 in the expression of late LTP and long-term memories. Nat Neurosci 4:289-296.

McDonald RJ, White NM (1993) A triple dissociation of memory systems: Hippocampus, amygdala, and dorsal striatum. Behav Neurosci 107:3-22.

McGaugh JL (2004) The amygdala modulates the consolidation of memories of emotionally arousing experiences. Annu Rev Neurosci 27:1-28.

Meibach RC, Siegel A (1977) Thalamic projections of the hippocampal formation: evidence for an alternate pathway involving the internal capsule. Brain Res 134:1-12.

Naber PA, Caballero-Bleda M, Jorritsma-Byham B, Witter MP (1997) Parallel input to the hippocampal memory system through peri- and postrhinal cortices. Neuroreport 8:2617-2621.

Okuno $\mathrm{H}$, Miyashita $\mathrm{Y}$ (1996) Expression of the transcription factor Zif268 in the temporal cortex of monkeys during visual paired associate learning. Eur J Neurosci 8:2118-2128.

Olton DS, Walker JA, Gage FH (1978) Hippocampal connections and spatial discrimination. Brain Res 139:295-308.

Olton DS, Walker JA, Woolf WA (1982) A disconnection analysis of hippocampal function. Brain Res 233:241-253.

Packard MG, Chen SA (1999) The basolateral amygdala is a cofactor in memory enhancement produced by intrahippocampal glutamate injections. Psychobiology 27:377-385.

Packard MG, Wingard JC (2004) Amygdala and 'emotional' modulation of the relative use of multiple memory systems. Neurobiol Learn Mem 82:243-252.

Parker A, Gaffan D (1997) The effect of anterior thalamic and cingulate cortex lesions on objects-in-place memory in monkeys. Neuropsychologia 35:1093-1102.

Paxinos G, Watson C (1997) The rat brain in stereotaxic coordinates. New York: Academic Press.

Pitkanen A (2000) Connectivity of the rat amygdaloid complex. In: The amygdala: a functional analysis (Aggleton JP, ed). Oxford: Oxford University Press. 
Savage LM, Chang Q, Gold PE (2003) Diencephalic damage decreases hippocampal acetylcholine release during spontaneous alternation testing. Learn Mem 10:242-246.

Shi CJ, Cassell MD (1997) Cortical, thalamic, and amygdaloid projections of rat temporal cortex. J Comp Neurol 382:153-175.

Shibata $\mathrm{H}$ (1993a) Efferent projections from the anterior thalamic nuclei to the cingulate cortex in the rat. J Comp Neurol 330:533-542.

Shibata H (1993b) Direct projections from the anterior thalamic nuclei to the retrohippocampal region in the rat. J Comp Neurol 337: $431-445$.

Stokes KA, Best PJ (1988) Mediodorsal thalamic lesions impair radial maze performance in the rat. Behav Neurosci 102:294-300.

Stokes KA, Best PJ (1990) Response biases do not underlie the radial maze deficit in rats with mediodorsal thalamus lesions. Behav Neural Biol 53:334-345.

Swanson LW (1992) Brain maps: Structure of the rat brain. Amsterdam: Elsevier Science Publishers.

Tischmeyer W, Grimm R (1999) Activation of immediate early genes and memory formation. Cell Mol Life Sci 55:564-574.

Van der Werf YD, Jolles J, Witter MP, Uylings HBM (2003) Contributions of thalamic nuclei to declarative memory functioning. Cortex 39:1047-1062.

Van der Werf YD, Witter MP, Uylings HBM, Jolles J (2000) Neuropsychology of infarctions in the thalamus: a review. Neuropsychologia 38:613-627.

Vann SD, Brown MW, Aggleton JP (2000a) Fos expression in the rostral thalamic nuclei and associated cortical regions in response to different spatial memory tests. Neuroscience 101:983-991.

Vann SD, Brown MW, Erichsen JT, Aggleton JP (2000b) Fos imaging reveals differential patterns of hippocampal and parahippocampal subfield activation in rats in response to different spatial memory tasks. J Neurosci 20:2711-2718.

Vann SD, Brown MW, Erichsen JT, Aggleton JP (2000c) Using Fos imaging in the rat to reveal the anatomical extent of the disruptive effects of fornix lesions. J Neurosci 20:8144-8152.
Vertes RP, Hoover WB, Viana Di Prisco G (2004) Theta rhythm of the hippocampus: Subcortical control and functional significance. Behav Cog Neurosci Rev 3:173-200.

Warburton EC, Baird AL, Morgan A, Muir J, Aggleton JP (2000) Disconnecting hippocampal projections to the anterior thalamus produces deficits on tests of spatial memory in rats. Eur J Neurosci 12:1714-1726.

Warburton EC, Baird AL, Morgan A, Muir J, Aggleton JP (2001) The conjoint importance of the hippocampus and anterior thalamic nuclei for allocentric spatial learning: Evidence from a disconnection study in the rat. J Neurosci 21:7323-7330.

Ward-Robinson J, Coutureau E, Good M, Honey RC, Killcross AS, Oswald CJ (2001) Excitotoxic lesions of the hippocampus leave sensory preconditioning intact: implications for models of hippocampal function. Behav Neurosci 115:1357-1362.

Winer BJ (1971) Statistical principles in experimental design. New York: McGraw-Hill.

Wisden W, Errington ML, Williams S, Dunnett SB, Waters C, Hitchcock D, Evan G, Bliss TV, Hunt SP (1990) Differential expression of immediate early genes in the hippocampus and spinal cord. Neuron 4:603-614.

Witter MP, Groenewegen HJ, Lopes da Silva FH, Lohman AHM (1989) Functional organisation of the extrinsic and intrinsic circuitry of the parahippocampal region. Prog Neurobiol 33:161253.

Witter MP, Wouterlood FG (2002) The parahippocampal region: organisation and role in cognitive functions. Oxford: Oxford University Press.

Zangenehpour S, Chaudhuri A (2002) Differential induction and decay curves of c-fos and zif268 revealed through dual activity maps. Mol Brain Res 109:221-225.

Zhang J, Slane E, McQuade JM, Vorhees CV, Xu M (2002) Hippocampal expression of $\mathrm{c}$-fos is not essential for spatial learning. Synapse 46:91-99. 